\title{
Socio-medical studies of individuals self-treating with helminths suggest that most clinical trials assessing helminth therapy may be designed to fail
}

\author{
Aarushi Venkatakrishnan ${ }^{1}$, Joshua T. Sarafian ${ }^{1}$, Kateřina Jirků-Pomajbíková ${ }^{2,3}$, William Parker ${ }^{1}$
}

${ }^{1}$ Department of Surgery, Duke University School of Medicine, Durham, NC, USA

${ }^{2}$ Institute of Parasitology, Biology Centre, Czech Academy of Sciences, 37005 České Budějovice, Czech Republic

${ }^{3}$ Faculty of Science, University of South Bohemia, 37005 České Budějovice, Czech Republic

Correspondence: $\quad$ William Parker, Ph.D.

Department of Surgery

Duke University Medical Center, Box 2605

Phone 919-681-3886

E-mail: William.Parker@Duke.edu

\begin{abstract}
The virtually complete loss of intestinal worms, known as helminths, from Western society has resulted in elimination of a range of helminth-induced morbidities. Unfortunately, that loss has also led to inflammation-associated deficiencies in immune function, ultimately contributing to widespread pandemics of allergies, autoimmunity, and neuropsychiatric disorders. Several socio-medical studies have examined the effects of intentional reworming, or self-treatment with helminths, on a variety of inflammation-related disorders. In this study, the latest results from ongoing socio-medical studies are described. The results point toward two important factors that appear to be overlooked in some if not most clinical trials. Specifically, (a) the method of preparation of the helminth can have a profound effect on its therapeutic efficacy, and (b) variation between individuals in the effective therapeutic dosage apparently covers a 10 -fold range, regardless of the helminth used. These results highlight current limits in our understanding of the biology of both hosts and helminths, and suggest that information from selftreatment may be critical in moving the field forward into mainstream medicine.
\end{abstract}

Keywords: helminth; helminthic therapy; biological therapy; inflammation; anti-inflammatory 


\section{Introduction}

Intestinal worms, called helminths, have been almost completely eliminated in Western countries by widespread use of toilets, refrigerators, food storage technologies, and various food preservation techniques. Although helminths in general cause a significant burden of disease, many helminths are benign (1) and, as a result, remain relatively unknown. Unfortunately, the loss of all helminths, both pathogenic and benign, from the ecosystem of the human body profoundly increases the propensity for chronic inflammation-associated disease in Western Society $(2,3)$. For example, in the 1970 s, seminal observations made by investigators in the UK demonstrated that exposure to helminths was critical for the elimination of allergic disease $(4,5)$. Later studies pointed toward the idea that exposure to helminths is also important for the prevention of autoimmune diseases $(6,7)$ and some neuropsychiatric disorders $(8)$. In light of this information, it is perhaps unsurprising that thousands of individuals today use helminths to treat their chronic inflammatory conditions (8-10).

Systematic data gathering from people "self-treating" with helminths was first suggested by Flowers and Hopkins in 2013 (11) as an effective method for obtaining information regarding the effects of therapeutic helminths on patients with chronic immune related disease. Unfortunately, clinical trials approved by regulatory agencies probing the effectiveness of helminth therapy have been limited, in part by intellectual property rights (12) and regulatory issues (13). Thus, at the present time, systematic data gathering from individuals self-treating may be the most practical and effective means of evaluating the effects of helminth therapy.

Previous studies collecting information from individuals self-treating with helminths (8-10) have encompassed four helminths, a wide range of disease, and more than 1000 individual cases. Data collection methods include surveys, interviews with helminth providers, and interviews with physicians who have experience observing patients who are self-treating. Information concerning the use of four helminths has been collected: the porcine whipworm (TSO), the human whipworm (TTO), the human hookworm (NA), and the rat tapeworm (HDC). This assortment of helminths was "selected" for use by self-treaters more by happenstance than by design (14), but provides a range of alternatives for self-treaters in terms of both financial costs and benefit/risk ratios (14).

In this study, we provide a series of new findings that add to our previous socio-medical studies. Importantly, new information highlights the importance of two factors that may not be adequately considered in some recent clinical trials: (a) individualized dosage requirements and (b) helminth preparation and storage conditions. These findings suggest that the current "gold standard" trials (15), despite their double-blind, placebo-controlled design, are providing false negative results due to a lack of consideration of the biology of helminths and their interactions with their hosts.

\section{Methods}

\section{General methods}

Studies were approved by the Duke Institutional Review Board. At no time was any protected health information gathered, and no personally identifying information was collected, ensuring anonymity of the participants. This study, as with our previous studies $(8,9)$, utilized multiple approaches to probe 
the outcomes of self-treatment with helminths. As previously described (9), the multiple methodologies facilitated acquisition of more diverse information than would have been obtainable with a single method alone, and allowed triangulation between methods to strengthen conclusions regarding some aspects of the practice of self-treatment with helminths. In this study, three approaches were used to evaluate current practice and outcomes in self-treatment with helminths. First, individuals prominent in the self-treatment community were interviewed. These included individuals producing, selling, and/or distributing helminths ("providers") for self-treatment with helminth therapy, and individuals compiling and organizing data regarding outcomes of self-treatment in a public format. As a second approach, publicly available information regarding self-treatment with helminths was compiled and evaluated. Third, physicians (all board-certified MDs) who see patients that self-treat with helminths were interviewed.

\section{Assessment of dosing recommendations by evaluation of publicly available information}

To provide information regarding the range of hookworm doses used for self-treatment, publicly available, self-reported personal experiences with dose adjusting using the human hookworm were examined. Helminthic Therapy Wiki ("Helminth Wiki"), a popular crowd-sourced site that consolidates information about helminth therapy, was used as an initial source of information. Most of the reports on Helminth Wiki came from a Yahoo group, "Helminthic Therapy Forum," and the "Helminthic Therapy Support" Facebook Group. While the Yahoo group was the longest active forum for helminth users, in December 2019 Yahoo removed all user content from its groups, leaving the information to be solely held on Helminthic Therapy Wiki. In the Facebook group, posts between January 2012 and December 2019 in were reviewed and users' personal experiences with dose adjustments were recorded. Two illnesses with the highest number of selected cases on the Wiki site were evaluated: Allergy and Crohn's colitis. Independent searches were conducted using the keywords "Allergy" or "Crohn's" and modifying the parameters to focus on a specific year in the date range. Cases were omitted if (a) the physical condition was not either allergies or Crohn's colitis, (b) the dose of helminths used was not specified, or (c) any helminth other than the hookworm was used, even if it was used in combination with the hookworm. Since this study was focused on the dosage used for effective therapy, cases that did not report a positive effect of helminth therapy were also excluded. In all remaining cases, the doses of helminth used were recorded and analyzed.

\section{Results}

\section{General}

The four helminths currently used for self-treatment are the same ones that have been used for about 7 years. The most recent addition for self-treaters was the rat tapeworm (HDC) in 2013. However, the popularity of various helminths continues to shift, with the human whipworm (TTO) becoming less popular due to a relatively high cost/benefit ratio compared to other helminths, and a lack of advantages over other helminths (Table 1). The observation that HDCs appear to be an effective therapeutic substitute for TTO was made by one of the most experienced helminth suppliers and has not been previously reported. Given that HDCs have a lower risk profile than TTO, it is anticipated that HDCs will continue to increase in popularity, while TTO decreases in popularity. However, the choice between different helminths for most individuals continues to be a balance between higher-cost helminths (TSO and HDC) that do not effectively colonize humans, and lower cost helminths that effectively colonize humans (TTO and NA). Further, it is expected that individuals who have had success with TTO in the past will continue to use the organism for therapeutic purposes.

\section{Growth of self-treatment}

No therapeutic helminth has yet been approved for use by the FDA. Further, at least two suppliers have tried to obtain approval through regulatory agencies for helminths as a novel food. These efforts have thus far not met with success. Nevertheless, self-treatment with helminths has continued to grow as judged by the number of companies currently providing helminths. The total number of helminth 
suppliers more than doubled between 2014 and 2020 (Figure 1). A list of current suppliers can be found in Table 2. The table excludes commercial suppliers who informed the study team that they did not wish to be publicly identified. In addition, "helmTX" is not included. Although they describe their helminth as "FDA approval pending", they do not currently provide helminths for self-treaters. Suppliers include some established brick and mortar facilities (e.g., Tanawisa, Biome Restoration, Worm Therapy, The Llamas Clinic) as well as others who can only be found on the internet or via Email (e.g., Autoimmune Therapies, Au Naturel, YourSymbionts). As shown in Figure 1, the number of suppliers providing HDCs and NA has expanded considerably. TSO, on the other hand, continues to be produced only by Tanawisa.

\section{Publicly organized data: Helminth Therapy Wiki}

Information regarding helminth therapy from social media groups such as Facebook and Yahoo has been available to the public for a number of years (9). Perhaps the biggest development in terms of social organization for self-treaters is the extensive development of a website designated exclusively for helminth therapy results. This website, "Helminthic Therapy Wiki", is regularly curated, gleaning information from the web as well as published information related to helminth therapy. The website compiles information on suppliers, financial costs of therapy, financial arrangements used by various suppliers (subscription, one-time payment, or contracts), treatment regimens, and results.

\section{One size does not fit all: the effective dose of helminth varies from individual to individual}

All helminths for which sufficient data from physicians and helminth suppliers have been obtained (HDCs, NA, and TSO) indicate that the effective dose of a given helminth is highly variable from individual to individual. The effective dose ranges for HDCs, for NA, and for TSO each vary by more than 10-fold, and are shown in Table 3.

A process of "dose-finding" for helminths has been developed and is recommended by most suppliers of helminths. In addition, six out of the seven physicians interviewed who provide information to patients self-treating also supported the dose-finding approach as being safer than attempting therapy with a "standard" dose defined as an effective dose for an average individual (Table 3). The dose finding approach entails starting with a low dose of helminth and then slowly working up to higher doses until either (a) symptom relief is obtained or (b) adverse side effects are sufficient to warrant backing off on the dosage or cessation of the protocol. This dose-finding protocol has been described previously for HDCs (10). Dose finding is also readily achieved for TSO given its stability during storage in a liquid suspension and relative frequency of administration on a weekly basis. However, it was noted by two suppliers that dose finding for NA can be time prohibitive. Because maturation of hookworm in the human body is a time consuming process requiring 6 to 8 weeks to achieve peak effects on immune function (16), and because approximately three months are often recommended between doses of NA for self-treatment, a dose finding scheme involving gradual escalation of NA could take years. In cases where the disease state is debilitating or progressive, this time frame may be unacceptable. Indeed, the single physician who did not support dose finding by gradual escalation of exposure worked exclusively with patients self-treating with NA. That said, another physician interviewed was adamant that failure to start at low exposure levels of NA was irresponsible and fraught with problems.

Assessment of publicly available information regarding the treatment of allergies and Chron's colitis using NA (see Methods) was used to glean further information regarding the dose range for NA. As shown in Figure 2, the number the organisms reported to be effective varied over a 10-fold range, both for the treatment of allergies and for the treatment of Crohn's. This observation held true for both the starting dose and the total number of helminths taken over time. Perhaps unexpectedly, the average effective dose did not vary significantly as a function of disease (Figure 2). A significant but weak association was observed between the starting dose and the cumulative dose per year (Figure 3), suggesting that some hesitancy on the part of some individuals rather than objective dose-finding schemes 
may underlie their relatively lower doses. However, because only successful cases were considered, it also seems likely that some unknown number of individuals starting at higher doses were excluded due to adverse events. With that in mind, those individuals starting at the higher doses may be self-selected for individuals who tolerated higher doses, thus providing a correlation between starting dose and cumulative dose. Nevertheless, correlations between initial doses and cumulative dose per year were not strong, indicating that many individuals adjust their dose either up or down during the course of their treatment with NA (Figures 2 and 3).

\section{Miscellaneous new observations on the practice of helminth therapy}

As mentioned above, one important new observation made by a supplier with extensive experience with multiple organisms was that HDCs are apparently as effective as TTO for treatment of ulcerative colitis, the primary indication for TTO. If this observation bears out, it is encouraging news, since the HDC has a better adverse side effect profile than does TTO. The same supplier also observed that extensive washing of NA for the purpose of removing bacteria prior to administration can profoundly diminish its effectiveness. Since cleaning the organisms is now standard for all FDA-approved trials, this observation might suggest that doses of NA used by self-treaters (e.g., Table 3, Figure 2 and 3) may be insufficient in clinical trials.

Cases of individuals being colonized with therapeutic HDCs continue to surface, although they are not common, and they occur primarily in children or in immunosuppressed adults. One case of a child being colonized with TSO has been reported through our socio-medical study, and it is believed that this case did not involve cross-contamination with TTO. (TTO and TSO can easily be mistaken for each other without appropriate assessment using genetic tools.) Although some cases of colonization of adults with TSO have been reported in the literature (17-19), R. J. Beer in 1976 described the eggs produced by TSO in humans as being unhealthy or "degenerate", and described the colonization as benign (without overt pathology). Further, different strains of TSO exist (20), and it is unknown whether specific characteristics of the strain used for therapy might affect colonization tendencies in humans. Nevertheless, it seems likely that none of the current helminths in use are completely non-colonizing in humans. Persistence in some cases may be expected, even if it is rare. Since these organisms can in rare cases persist long enough to produce eggs, they should be described as "poorly colonizing" or "weakly colonizing" rather than "non-colonizing".

NA has frequently been administered on the forearm. However, treatment with NA by most selftreaters now utilizes application to the feet rather than the forearm. The view that this approach causes substantially less irritation at the site of entry of the organisms was corroborated by two physicians and one supplier.

Mast cell disorders and fibromyalgia have previously been reported to be contra-indications for helminth therapy. This conclusion has been corroborated by an additional supplier. In addition, a supplier with extensive experience in the application of helminth therapy and with ties to a clinic treating patients with helminths reports that fistulating Crohn's disease is also a contra-indication for helminth therapy.

\section{A persistent question: Does preparation and storage of TSO affect its efficacy?}

TSO is the organism that has been most often used by individuals self-treating with helminths (9). However, the therapeutic effect of the organism has not born out well in clinical trials $(21,22)$. Despite this failure, our socio-medical study continues to receive reports, consistent with earlier successful trials $(23,24)$, that TSO is indeed effective. An explanation for these conflicting observations is adamantly supported by the supplier of TSO. Prior to the report of the first failure of a clinical trial with TSO, our socio-medical study received reports from the supplier that clinical trials utilized organisms that were poorly prepared, thereby decreasing their efficacy (9). The central question regarding preparation of the organism deals with the acidity of the solution in which the organisms are suspended: $\mathrm{pH}$ of storage, how 
fast the $\mathrm{pH}$ is changed prior to administration to patients, and how long it sits at a particular $\mathrm{pH}$ prior to administration.

As mentioned above and discussed previously (9), controversy regarding the preparation of TSO centers around the $\mathrm{pH}$ of the preparation. During the initial isolation of TSO in preparation for clinical use, the $\mathrm{pH}$ is lowered dramatically ( $\mathrm{pH}$ approximately 1.0) to inactivate pathogens that may be present in the porcine feces from which TSO is harvested. Then the $\mathrm{pH}$ is raised at least to $\mathrm{pH} 2.5$ prior to storage. This process differs substantially from the $\mathrm{pH}$ encountered by the organism during its natural life cycle, in which a low $\mathrm{pH}$ is only temporarily encountered in the distal porcine stomach immediately following ingestion (Figure 4). As shown in Figure 4, the pH of therapeutic preparations of TSO can vary dramatically and depends on the preparation. Further, the method of raising the $\mathrm{pH}$ following initial preparation can vary, and the length of time in storage after raising the $\mathrm{pH}$ can vary. The manufacturer of TSO for self-treatment contends that only by raising moderately (i.e., up to $\mathrm{pH} 2.5$ ) and slowly can effective TSO be maintained. Based on their customer feedback, they contend that raising the $\mathrm{pH}$ to as high as 5.5 prior to storage can render the TSO ineffective over time. Despite the fact that TSO has been used in clinical trials, the effect of $\mathrm{pH}$ on the viability of the organism and its ability to hatch has not been investigated. Some work has been done with the mouse whipworm (25), but results from studies using the mouse whipworm may not apply to the porcine whipworm (26).

Given that helminth suppliers often receive regular feedback on their preparations from their customers, their measure of efficacy can be both extremely rapid and clinically relevant. Individuals running clinical trials, on the other hand, must rely on surrogate markers, such as the hatching of the organisms in an animal model. Unfortunately, at least for the HDC, measures in laboratory animals are ineffective. Several factors, including advanced age of the organisms and feeding extremely rich diets to their hosts, apparently harm the therapeutic benefit of the organisms (10) without impeding the ability of the organisms to mature in their native hosts. It is indeed difficult to imagine how such sensitivity to the conditions of preparation could be elucidated in clinical trials. The argument has been made that, because the organisms produce some adverse side effects in clinical trials, they must be viable. While this argument certainly has merit, the nature of the side effects is of interest. As an example, Figure 5 shows intestinal distress reported in one trial (27). In that trial, in which TSO proved to be ineffective at the dose used, a significant amount of GI distress in most patients following the second dose of the organism was observed, although the GI distress did not persist despite continued treatment. It is unclear whether this temporary increase in side effects demonstrates that the organisms used for the duration of the trial were active, and it is also unclear whether this side effect correlates with the potential for clinical effectiveness.

\section{Discussion}

At the present time, several clinical trials, reviewed recently (15), have been published using TSO (21), while others have been published using NA $(16,28)$. Despite numerous positive results in animal models, results in clinical trials have been disappointing (22). Unfortunately, investigators have not taken into account the greater than 10-fold dose range, depending on the individual, that is apparently required to achieve a satisfactory effect. This issue applies to all potentially therapeutic helminths studied to date, and presents considerable challenges to clinical trials that would incur considerable time and expense with the implementation of any lengthy dose-finding scheme. Furthermore, investigators have apparently been largely unaware that the effectiveness of therapeutic helminths can depend on the production and storage conditions. This latter issue is a factor for HDCs and possibly for TSO and NA as well. Based on this assessment, we conclude that the conduct of clinical trials needs to be altered significantly, taking into account the biology of helminths as well as the variable immunology of their hosts. If the current trends continue, it seems possible that the therapeutic potential of helminths will be overlooked 
in favor of pharmacological therapies that are more expensive and potentially less effective. Of considerable concern in this regard is the view that exposure to benign helminths is probably a reasonable preventative measure, whereas treatment with helminth derived products is expected to be utilized only after disease has occurred.

A variety of factors indicate that results reported to us through socio-medical studies are representative of the actual effects of helminth therapy, not artifacts due to placebo effects, normalization to the mean, survivor bias, conflicts with commercial interests, or other issues unrelated to the actual benefits and risks of the therapy. These factors are as follows:

- Survivor bias has been eliminated using some data collection methods (e.g., interviews with physicians and a survey collection method supported by a helminth supplier).

- Reviews, both positive and negative, made by individuals (typically experienced physicians or suppliers) with multiple observations are consistent and corroborating (independent of the commercial interest of the source).

- Reported beneficial effects of therapy are long lasting if the therapy is maintained, inconsistent with the placebo effect.

- Therapy is reported to effectively treat chronic conditions present for decades and despite multiple failures with pharmaceutical approaches, inconsistent with normalization to the mean.

- Therapy has been used to treat degenerative conditions that are irreversible, such as multiple sclerosis, inconsistent with normalization to the mean.

- Beneficial effects of therapy often surprise the users, inconsistent with the placebo effect.

- Therapy has been reported to be effective in small children, who are not prone to influence by expectations or preconditioning.

- Self-treaters indicate that they can tell when their beneficial helminths lose effect and acquisition of more organisms is required. The timing is helminth specific, indicating that the reports are based on a phenomenon related to helminth biology, not human psychology.

- The effects reported by self-treaters are supported by numerous studies in animal models.

The adverse side effects associated with uncontrolled colonization with helminths and perhaps to a lesser extent clinical trials with helminth therapy has led some research groups to pursue helminth derived products (HDPs) rather than helminths themselves as a treatment for inflammatory diseases $(29,30)$. In January 2020, Capron et al. published the first clinical trial to evaluate the safety of the recombinant helminth protein, P28GST from Schistosoma haematobium, in patients with mild or inactive Crohn's disease (31). P28GST was first developed as a vaccine against schistosomiasis, however, researchers have found that the protein has a positive effect in humans and other animal models against inflammation (31-34). Through 
their pilot study, they found that the patients experienced a positive response and they claimed that using HDPs are a more promising approach as they can replicate the benefits of helminthic therapy without the detriments. The view is that, because the immunomodulatory effectiveness of helminths can be attributed to their surface or excretory/secretory products, therapies can be designed using only these key products (35). Thus, some researchers, while recognizing the potential benefits of helminthic therapy, have turned away from the use of live helminths and instead pursued HDPs (35-37). At the present time, however, we do not agree that this approach is warranted. Here we describe evidence that the efficacy of helminth therapy can be improved and the adverse effects of the therapy can be reduced using personalized dose adjustments over time. Further, we continue to argue that controlled, moderate exposure to domesticated, benign helminths is a practical and cost-effective solution to undermining increases in a variety of hyper-immune related diseases in Western culture (38).

\section{Conclusions}

Helminth therapy addresses a fundamental cause of disease in Western society. In particular, helminth therapy reverses the loss of helminths in Western society that has left the immune system overreactive and prone to allergic, autoimmune, and neuropsychiatric disorders $(2,3)$. At the present time, we would argue that the primary "lab" for helminth therapy seems to be within the community of self-treaters. This "biohacking" phenomena of science outside of the established main stream is not unique to helminth therapy. However, given that helminth therapy addresses a fundamental cause of disease in Western society, this particular biohacking endeavor may in fact be critical for public health. Unfortunately, for a variety of economic, regulatory, and practical issues surrounding the conduct of clinical trials, main stream trials have thus far been unable to accommodate the nuances of helminth therapy. Foremost among the issues that clinical trials must address before they can effectively test the potential for helminth therapy are (a) details in formulation of the helminth product that affect efficacy, and (b) the very wide range of doses typically needed within a cohort of individuals.

\section{Acknowledgements}

The authors would like to thank the physicians, suppliers, and others knowledgeable regarding the self-treatment with helminths for altruistically providing the information compiled in this manuscript.

\section{Conflicts of Interest}

The authors report no conflict of interest and no financial interests in helminth therapy. Authors AT, JTS, and WP are affiliated with Duke University Medical Center, which has a vested interest in technology involving the therapeutic use of Hymenolepis diminuta. 


\section{Tables}

\begin{tabular}{|c|c|c|}
\hline Helminth & pros & cons \\
\hline NA & $\begin{array}{l}\text { - May be more potent that other } \\
\text { helminths under some conditions, } \\
\text { especially for lung-associated } \\
\text { conditions. } \\
\text { - Least expensive of all helminths: } \\
\text { Easy to self-cultivate. } \\
\text {-Abundant data from self-treaters } \\
\text { available. }\end{array}$ & $\begin{array}{l}\text {-Beneficial effects can take months to mature: } \\
\text { tittering dose is time-prohibitive in many cases. } \\
\text {-Side effects from over-exposure can be severe. } \\
\text {-Isolated from human feces. } \\
\text {-Purification (cleaning) for FDA-approved use } \\
\text { may adversely affect the organisms' efficacy. } \\
\text {-Clinical data available, but probably do not } \\
\text { reflect optimized therapeutic approach. } \\
\text {-Utilizes blood for survival. }\end{array}$ \\
\hline TSO & $\begin{array}{l}\text { - Best tested for safety in clinical trials. } \\
\text { - Almost always non-colonizing. } \\
\text { - Minimal or no side effects when dose } \\
\text { is carefully titrated. }\end{array}$ & $\begin{array}{l}\text { Currently more expensive than other helminths. } \\
\text { Impossible to cultivate without extensive } \\
\text { resources. } \\
\text { - Can take longer than HDCs for beneficial effects } \\
\text { to mature. } \\
\text { - Clinical data available, but probably do not } \\
\text { reflect optimized therapeutic approach } \\
\text { - Isolated from pig feces. } \\
\text {-Storage conditions, especially the pH, are } \\
\text { potentially important but have not been agreed } \\
\text { upon by the scientific community. } \\
\text { - Limited data from self-treating community } \\
\text { available. }\end{array}$ \\
\hline HDC & $\begin{array}{l}\text {-Usually non-colonizing. } \\
\text { - Minimal or no side effects when dose } \\
\text { is carefully titrated. } \\
\text {-Faster acting than other helminths. } \\
\text { (Beneficial effects mature faster.) } \\
\text {-Isolated from an edible host (grain } \\
\text { beetle) } \\
\text {-Abundant data from self-treaters } \\
\text { available. } \\
\text {-Does not encroach on host tissue: } \\
\text { remains in the lumen of the gut. }\end{array}$ & $\begin{array}{l}\text { - More expensive than NA. } \\
\text {-Time consuming to cultivate. Requires } \\
\text { specialized facilities. } \\
\text { - Rapid spoiling on storage, increasing cost of } \\
\text { shipping. }\end{array}$ \\
\hline TTO & -Well studied in isolated cases. & $\begin{array}{l}\text { - Can make disease worse in some cases. } \\
\text { - Time consuming and difficult to cultivate. } \\
\text { - Limited utility: Not suggested for most } \\
\text { conditions. Works well for ulcerative colitis, but } \\
\text { HDCs is also effective in those cases. }\end{array}$ \\
\hline
\end{tabular}

Table 1: pros and cons of each helminth currently used for therapeutic purposes by self-treaters. 


\begin{tabular}{|l|l|l|}
\hline Helminth Supplier Name & Helminth(s) provided & Year product released \\
\hline Tanawisa & TSO & 2004 \\
\hline \multirow{3}{*}{ Autoimmune Therapies } & NA & 2007 \\
\cline { 2 - 3 } & TTO & 2007 \\
\hline \multirow{3}{*}{ Worm Therapy } & NA & 2008 \\
\cline { 2 - 3 } & TTO & 2008 \\
\cline { 2 - 3 } & HDC & 2013 \\
\hline Biome Restoration Ltd & HDC & 2013 \\
\hline \multirow{2}{*}{ Symmbio } & NA & 2016 \\
\cline { 2 - 3 } & TTO & 2016 \\
\hline \multirow{2}{*}{ The Llamas Clinic } & NA & 2018 \\
\cline { 2 - 3 } & HDC & 2018 \\
\hline \multirow{2}{*}{ YourSymbionts } & NA & 2018 \\
\cline { 2 - 3 } & TTO & 2018 \\
\hline \multirow{2}{*}{$\begin{array}{l}\text { Helminth Therapy Aust \& NZ } \\
\text { (formerly Brisbane Naturopaths) }\end{array}$} & HDC & 2019 \\
\hline Au NAturel & NA & 2019 \\
\hline
\end{tabular}

Table 2. Current helminth suppliers, helminths supplied, and the date when access began. Most of the providers listed were at one time working with other suppliers or are still affiliated with other suppliers. 


\begin{tabular}{|l|c|c|c|}
\hline & \multicolumn{3}{|c|}{ Set Point (number of organisms / time) } \\
\hline & Low set point & Median set point & High set point \\
\hline Hookworm (NA) & $2-5 / 3$ months & $15-20 / 3$ months & $50 / 3$ months \\
\hline Porcine whipworm (TSO) & $200 / 2$ weeks & $2500 / 2$ weeks & $7500 / 10$ days \\
\hline Rat Tapeworm (HDC) & $2-5 / 6$ weeks & $20-40 / 4$ weeks & $200 / 1$ week \\
\hline
\end{tabular}

Table 3. Dose range for helminths commonly used for therapeutic purposes. Insufficient data for the use of human whipworms (TTO) exists to establish set point ranges. 


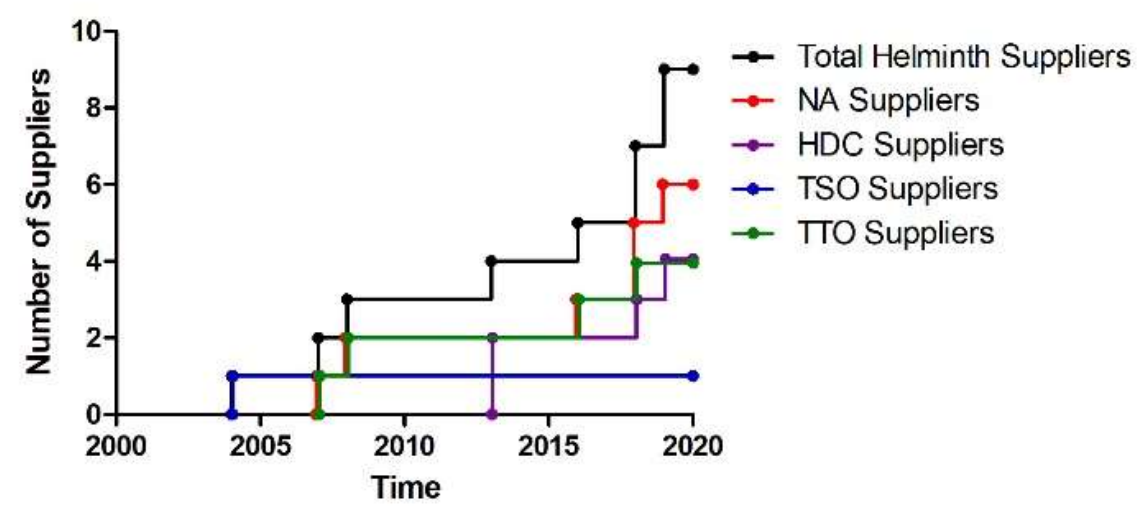

Figure 1. Emergence of companies selling various helminths. Only companies currently supplying helminths are shown on the graph; companies no longer in business are excluded. In addition, companies which do not wish to be recognized publicly are not shown on the graph. 
A

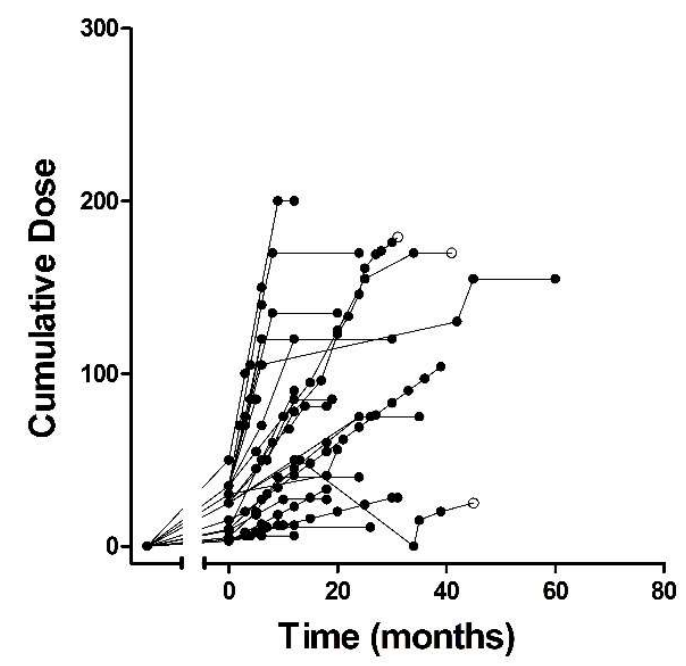

C

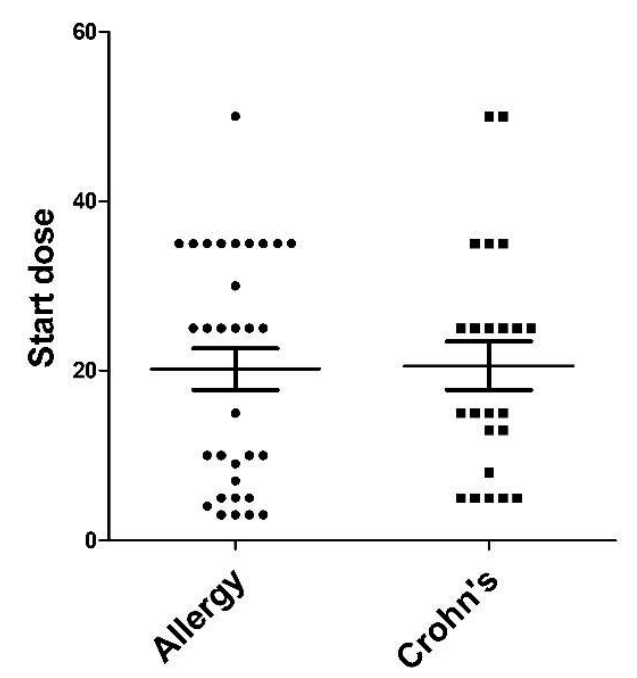

B

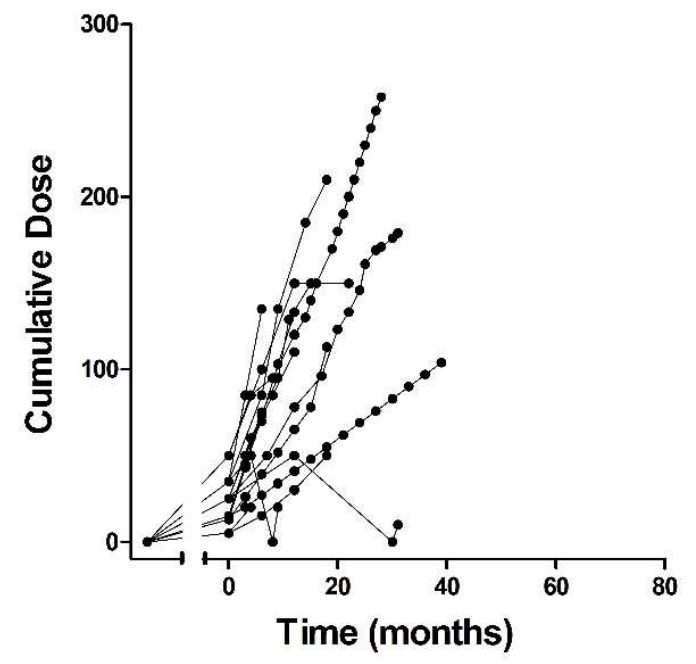

D

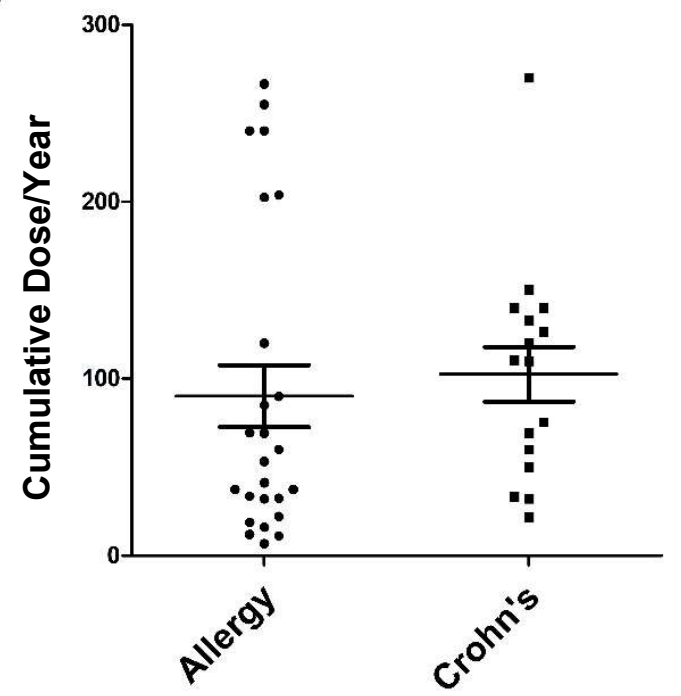

Figure 2: Variation in dosage of the human hookworm (NA) from self-reported, successful treatment of allergies and Crohn's colitis. The self-reported dosing strategy taken by individuals with allergies $(\mathrm{n}=25)$ and Crohn's $(\mathrm{n}=16)$ is shown in panels $\mathrm{A}$ and $\mathrm{B}$, respectively. Open circles represent instances where an individual determined that their dose was too high and started to worsen their condition. Panel $\mathbf{C}$ shows a comparison between the starting dose of NA taken between self-treaters with allergies $(n=32$, mean $=20.22$, std deviation $=13.88$, std error $=$ 2.454) and those with Crohn's $(n=23$, mean $=20.61$, std deviation $=13.62$, std error $=2.841) \mathrm{p}$ $=0.8696$. Panel $\mathbf{D}$ compares the cumulative dose, normalized per year, for self-treaters with allergies $(n=25$, mean $=90.25$, std deviation $=86.86$, std error $=17.57)$ and those with Crohn's $(\mathrm{n}=16$, mean $=102.6$, std deviation $=62.04$, std error $=15.51) \mathrm{p}=0.1857$. 

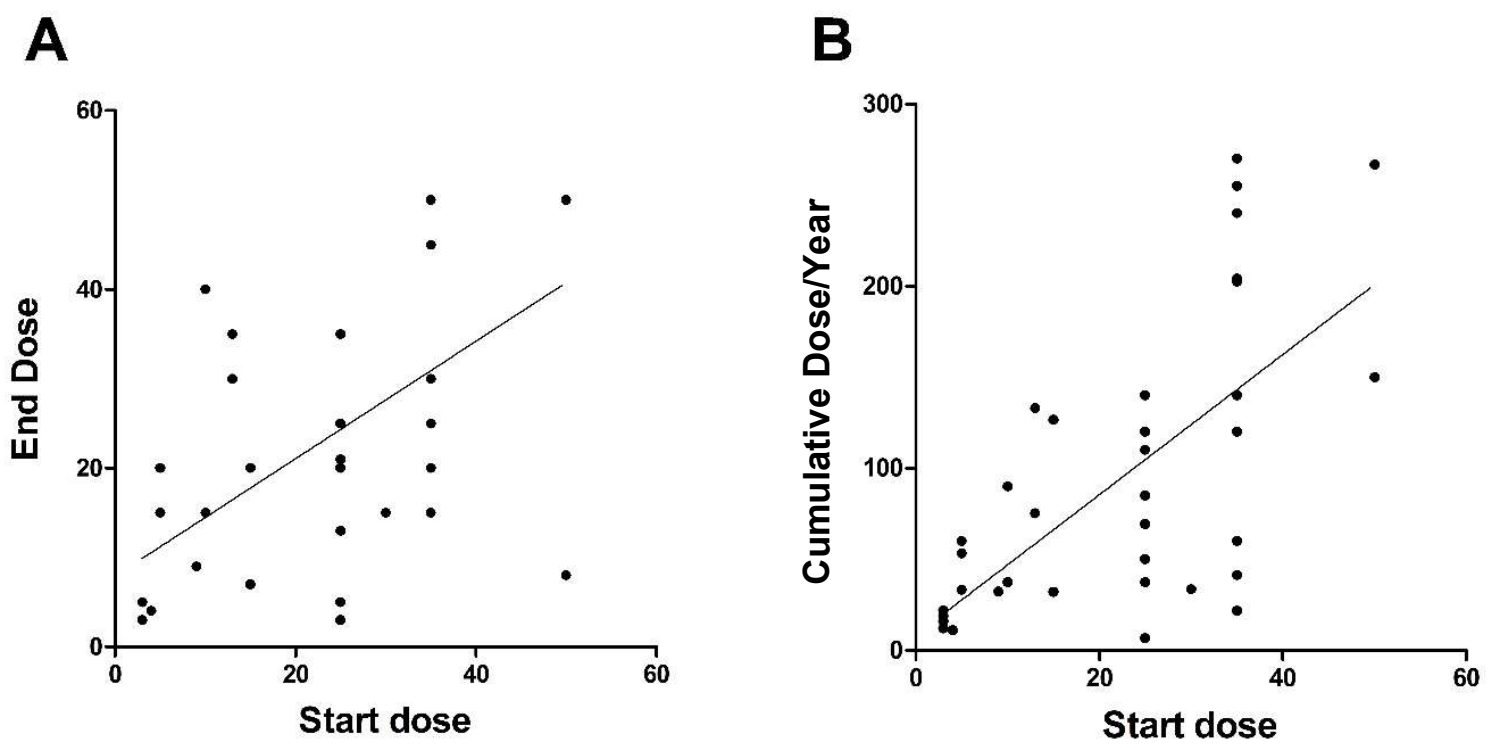

Figure 3: Relationship between the initial dose of hookworm and the last reported dose (A), and between the initial dose and the cumulative dose per year (B). For this analysis, self-reported data from individuals treating allergies and Crohn's colitis were combined and analyzed together. Correlations were statistically significant but weak for both comparisons: $\left(A, n=41, r^{2}\right.$ $=0.3159, \mathrm{p}=0.0001)\left(\mathrm{B}, \mathrm{n}=41, \mathrm{r}^{2}=0.4234, \mathrm{p}=<0.0001\right)$. The average time until last dose for allergies was 1.48 years (17.72 months), and was 1.31 years (15.69 months) for Crohn's colitis. 


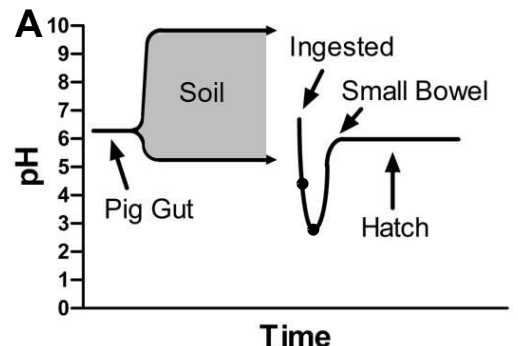

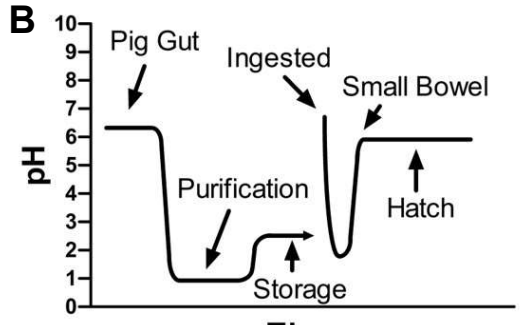

Time

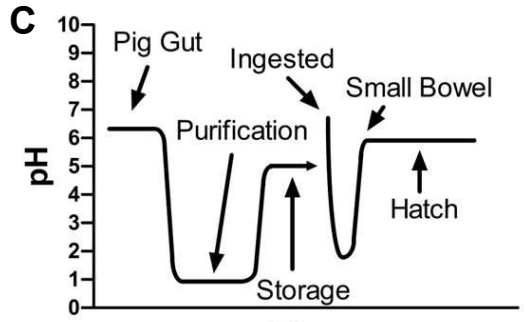

Time

Figure 4: Fluctuations in $\mathrm{pH}$ during $(\mathbf{A})$ the natural life cycle of TSO and during $(\mathbf{B}, \mathbf{C})$ two methods of preparation. After passing through the pig gut at $\mathrm{pH}$ 6.1-6.6, TSO is deposited in soil $(39,40)$. Geohelminths can survive in both slightly acidic and alkaline soils, with studies reporting presence of helminths between $\mathrm{pH} 5.21-9.9$ (41-43). Ingestion in the pig occurs between approximately $\mathrm{pH} 6.7$ (44), and acidity increases as the TSO reaches the pig's anterior stomach at $\mathrm{pH} 4.4$ and then the posterior stomach at $\mathrm{pH} 2.6(40,45,46)$. As the TSO reach the pig's small bowel between pH $6.1-6.7$, the helminth hatches. For use in humans, TSO is purified from pig feces using strongly acidic conditions $(\mathrm{pH} 1)$ to inactivate viruses $(\mathrm{B}, \mathrm{C})$. After purification, the TSO is either stored at a low $\mathrm{pH}$ of 2.5 (B), or a relatively higher $\mathrm{pH}$ of 5 (C). TSO is ingested by humans at approximately $\mathrm{pH} 6.7(47,48)$, and reaches the stomach at $\mathrm{pH} 1.7$ $(49,50)$. Lastly, the TSO hatches in the small bowel at $\mathrm{pH} 6$ (51). Arrows preceding breaks in the graph represent the TSO remaining in the soil or in storage for an unspecified time. 


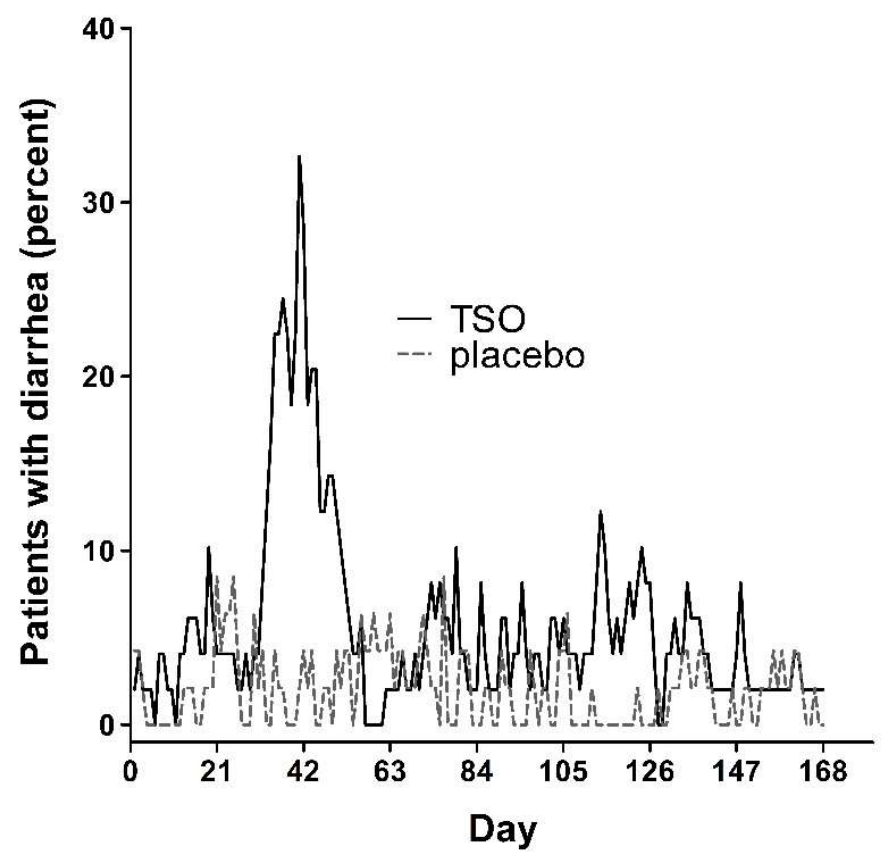

Figure 5: Percentage of patients in Bager et al.'s 2010 randomized, placebo-controlled clinical trial with TSO (27) who reported having diarrhea throughout the treatment course. For this trial, a dose of 2500 ova was taken 8 times at 21 day intervals. Days labeled in the graph indicated days in which a dose was administered, except that no dose was administered on day 168. A notable helminth-dependent increase in adverse effects peaked after the $2^{\text {nd }}$ dose, dissipating by the $4^{\text {th }}$ dose. Placebo $n=47$, TSO $n=49$. 


\section{References}

1. Parker W, Ollerton J; Evolutionary Biology and Anthropology Suggest Biome Reconstitution as a Necessary Approach toward Dealing with Immune Disorders. Evolution, Medicine, and Public Health 2013;2013:89-103. doi: 10.1093/emph/eot008.

2. Rook GAW; Review series on helminths, immune modulation and the hygiene hypothesis: the broader implications of the hygiene hypothesis. Immunology 2009;126(1):3-11.

3. Rook GAW; The hygiene hypothesis and the increasing prevalence of chronic inflammatory disorders. Transactions of the Royal Society of Tropical Medicine and Hygiene 2007;101(11):1072-1074.

4. $\quad$ Preston PJ; The biology of the atopic response. J R Nav Med Serv 1970;56(3):229-35.

5. $\quad$ Turton JA; IgE, parasites, and allergy. Lancet 1976;2(7987):686.

6. Correale J, Farez M, Razzitte G; Helminth infections associated with multiple sclerosis induce regulatory B cells. Annals of Neurology 2008;64(2):187-99.

7. Correale J, Farez M; Association between parasite infection and immune responses in multiple sclerosis. Annals of Neurology 2007;61(2):97-108.

8. Liu J, Morey RA, Wilson JK, et al.; Practices and outcomes of self-treatment with helminths based on physicians' observations. Journal of Helminthology 2016;FirstView:1-11.

9. Cheng $A M$, Jaint $D$, Thomas $S$, et al.; Overcoming evolutionary mismatch by self-treatment with helminths: current practices and experience. Journal of Evolutionary Medicine 2015;3:Article ID 235910.

10. Smyth K, Morton C, Mathew A, et al.; Production and Use of Hymenolepis diminuta

Cysticercoids as Anti-Inflammatory Therapeutics. Journal of Clinical Medicine 2017;6(10):98. doi: 10.3390/jcm6100098.

11. Flowers S, Hopkins M; Autoimmune disease: Patients self-treat with parasitic worms. Nature 2013;493(7431):163. doi: 10.1038/493163c.

12. Tilp C, Kapur V, Loging W, et al.; Prerequisites for the pharmaceutical industry to develop and commercialise helminths and helminth-derived product therapy. International Journal of Parasitology 2013;43:319-325. doi: 10.1016/j.ijpara.2012.12.003.

13. Bono-Lunn D, Villeneuve C, Abdulhay NJ, et al.; Policy and regulations in light of the human body as a 'superorganism' containing multiple, intertwined symbiotic relationships. Clinical Research and Regulatory Affairs 2016;33(2-4):39-48. doi: 10.1080/10601333.2016.1210159.

14. Sobotková K, Parker W, Levá J, et al.; Helminth Therapy - From the Parasite Perspective. Trends Parasitol 2019;35(7):501-515. doi: 10.1016/j.pt.2019.04.009.

15. Smallwood TB, Giacomin PR, Loukas A, et al.; Helminth Immunomodulation in Autoimmune Disease. Frontiers in immunology 2017;8:453-453. doi: 10.3389/fimmu.2017.00453.

16. Feary JR, Venn AJ, Mortimer K, et al.; Experimental hookworm infection: a randomized placebocontrolled trial in asthma. Clinical \& Experimental Allergy 2010;40(2):299-306.

17. Kradin RL, Badizadegan K, Auluck P, et al.; latrogenic Trichuris suis infection in a patient with Crohn disease. Arch Pathol Lab Med 2006;130(5):718-20. doi: 10.1043/1543-

2165(2006)130[718:itsiia]2.0.co;2.

18. Beer RJ; The relationship between Trichuris trichiura (Linnaeus 1758) of man and Trichuris suis (Schrank 1788) of the pig. Res Vet Sci 1976;20(1):47-54.

19. Beer RJ; Experimental infection of man with pig whipworm. Br Med J 1971;2(5752):44. doi: 10.1136/bmj.2.5752.44.

20. Hawash MBF, Betson M, Al-Jubury A, et al.; Whipworms in humans and pigs: origins and demography. Parasites \& Vectors 2016;9(1):37. doi: 10.1186/s13071-016-1325-8.

21. Huang $X$, Zeng L-R, Chen F-S, et al.; Trichuris suis ova therapy in inflammatory bowel disease: $\mathrm{A}$ meta-analysis. Medicine 2018;97(34):e12087-e12087. doi: 10.1097/MD.0000000000012087. 
22. Helmby H; Human helminth therapy to treat inflammatory disorders- where do we stand? $B M C$ Immunology 2015;16:12. doi: 10.1186/s12865-015-0074-3.

23. Summers RW, Elliott DE, Qadir K, et al.; Trichuris suis seems to be safe and possibly effective in the treatment of inflammatory bowel disease. American Journal of Gastroenterology 2003;98(9):203441.

24. Elliott DE, Summers RW, Weinstock JV; Helminths and the modulation of mucosal inflammation. Curr Opin Gastroenterol 2005;21(1):51-8.

25. Wimmersberger D, Tritten L, Keiser J; Development of an in vitro drug sensitivity assay for Trichuris muris first-stage larvae. Parasites \& Vectors 2013;6(1):42. doi: 10.1186/1756-3305-6-42.

26. Vejzagić N, Adelfio R, Keiser J, et al.; Bacteria-induced egg hatching differs for Trichuris muris and Trichuris suis. Parasites \& vectors 2015;8:371-371. doi: 10.1186/s13071-015-0986-z.

27. Bager P, Arnved J, Ronborg S, et al.; Trichuris suis ova therapy for allergic rhinitis: a randomized, double-blind, placebo-controlled clinical trial. Journal of Allergy \& Clinical Immunology 2010;125(1):12330 e1-3.

28. Feary J, Venn A, Brown A, et al.; Safety of hookworm infection in individuals with measurable airway responsiveness: a randomized placebo-controlled feasibility study. Clinical and experimental allergy : journal of the British Society for Allergy and Clinical Immunology 2009;39(7):1060-8.

29. Schölmerich J, Fellermann K, Seibold FW, et al.; A Randomised, Double-blind, Placebo-controlled Trial of Trichuris suis ova in Active Crohn's Disease. Journal of Crohn's \& colitis 2017;11(4):390-399. doi: 10.1093/ecco-jcc/jjw184.

30. Summers RW, Elliott DE, Urban JF, Jr., et al.; Trichuris suis therapy in Crohn's disease. Gut 2005;54(1):87-90. doi: 10.1136/gut.2004.041749.

31. Capron M, Béghin L, Leclercq C, et al.; Safety of P28GST, a Protein Derived from a Schistosome Helminth Parasite, in Patients with Crohn's Disease: A Pilot Study (ACROHNEM). Journal of clinical medicine 2019;9(1):41. doi: 10.3390/jcm9010041.

32. Riveau G, Deplanque D, Remoué F, et al.; Safety and immunogenicity of rSh28GST antigen in humans: phase 1 randomized clinical study of a vaccine candidate against urinary schistosomiasis. PLoS Negl Trop Dis 2012;6(7):e1704. doi: 10.1371/journal.pntd.0001704.

33. Riveau G, Schacht AM, Dompnier JP, et al.; Safety and efficacy of the rSh28GST urinary schistosomiasis vaccine: A phase 3 randomized, controlled trial in Senegalese children. PLoS Negl Trop Dis 2018;12(12):e0006968. doi: 10.1371/journal.pntd.0006968.

34. Sipahi AM, Baptista DM; Helminths as an alternative therapy for intestinal diseases. World J Gastroenterol 2017;23(33):6009-6015. doi: 10.3748/wjg.v23.i33.6009.

35. Ditgen D, Anandarajah EM, Meissner KA, et al.; Harnessing the Helminth Secretome for Therapeutic Immunomodulators. BioMed Research International 2014;2014:964350. doi: 10.1155/2014/964350.

36. Motran CC, Silvane L, Chiapello LS, et al.; Helminth Infections: Recognition and Modulation of the Immune Response by Innate Immune Cells. Frontiers in immunology 2018;9:664-664. doi: 10.3389/fimmu.2018.00664.

37. Sotillo J, Toledo R, Mulvenna J, et al.; Exploiting Helminth-Host Interactomes through Big Data. Trends in Parasitology 2017;33(11):875-888. doi: https://doi.org/10.1016/i.pt.2017.06.011.

38. Parker W, Perkins SE, Harker M, et al.; A prescription for clinical immunology: the pills are available and ready for testing. Current Medical Research and Opinion 2012;28:1193-1202. doi: 10.1185/03007995.2012.695731.

39. Merchant HA, McConnell EL, Liu F, et al.; Assessment of gastrointestinal pH, fluid and lymphoid tissue in the guinea pig, rabbit and pig, and implications for their use in drug development. Eur J Pharm Sci 2011;42(1-2):3-10. doi: 10.1016/j.ejps.2010.09.019. 
40. Callegari M, Novais A, Oliveira E, et al.; Microencapsulated acids associated with essential oils and acid salts for piglets in the nursery phase. Semina:Ciencias Agrarias 2016;37:2193-2208. doi: 10.5433/1679-0359.2016v37n4p2193.

41. Etewa SE, Abdel-Rahman SA, Abd El-Aal NF, et al.; Geohelminths distribution as affected by soil properties, physicochemical factors and climate in Sharkyia governorate Egypt. Journal of parasitic diseases : official organ of the Indian Society for Parasitology 2016;40(2):496-504. doi: 10.1007/s12639014-0532-5.

42. Sumbele IU, Ngole VM, Ekosse G-IE; Influence of physico-chemistry and mineralogy on the occurrence of geohelminths in geophagic soils from selected communities in the Eastern Cape, South Africa, and their possible implication on human health. International Journal of Environmental Health Research 2014;24(1):18-30. doi: 10.1080/09603123.2013.782600.

43. Amadi E, Uttah E; Impact of physico-chemical factors of contaminated foci on the survival of geohelminths in Abua Communities, Niger Delta Nigeria. Journal of Applied Sciences and Environmental Management 2010;14(4).

44. Lewis AJ, Southern LL. Swine Nutrition: CRC Press, 2000.

45. Merchant HA, McConnell EL, Liu F, et al.; Assessment of gastrointestinal pH, fluid and lymphoid tissue in the guinea pig, rabbit and pig, and implications for their use in drug development. European Journal of Pharmaceutical Sciences 2011;42(1-2):3-10. doi: 10.1016/j.ejps.2010.09.019.

46. Beasley DE, Koltz AM, Lambert JE, et al.; The Evolution of Stomach Acidity and Its Relevance to the Human Microbiome. PloS one 2015;10(7):e0134116-e0134116. doi: 10.1371/journal.pone.0134116. 47. Baliga S, Muglikar S, Kale R; Salivary pH: A diagnostic biomarker. Journal of Indian Society of Periodontology 2013;17(4):461-465. doi: 10.4103/0972-124X.118317.

48. Aoyama K-i, Okino Y, Yamazaki H, et al.; Saliva pH affects the sweetness sense. Nutrition 2017;35:51-55. doi: https://doi.org/10.1016/j.nut.2016.10.018.

49. Dressman JB, Berardi RR, Dermentzoglou LC, et al.; Upper Gastrointestinal (GI) pH in Young, Healthy Men and Women. Pharmaceutical Research 1990;7(7):756-761. doi:

10.1023/A:1015827908309.

50. Foltz E, Azad S, Everett ML, et al.; An assessment of human gastric fluid composition as a function of PPI usage. Physiol Rep 2015;3(1). doi: 10.14814/phy2.12269.

51. Fallingborg J; Intraluminal pH of the human gastrointestinal tract. Dan Med Bull 1999;46(3):18396. 